\title{
MI VICO. \\ ÚLTIMO BARROCO, PADRE DE LA ESTÉTICA Y DE LOS ESTUDIOS CULTURALES
}

\author{
Giuseppe Patella \\ (Universidad de Roma, Tor Vergata)
}

RESUMEN: Fiel al método viquiano que en la historia favorece los fragmentos, los residuos, los descartes, mi lectura de Vico siempre ha preferido los motivos descuidados y eliminados de su pensamiento, que he releído libremente buscando sobre todo hacerlos resonar en el horizonte actual del pensamiento. Así nacieron mis lecturas de un Vico teórico del cuerpo, pensador barroco, padre de la estética moderna y de los estudios culturales.

PalABRAS ClaVE: Vico, $350^{\circ}$ Aniversario, cuerpo, ingenio, Barroco, estética, estudios culturales, G. Patella.

\section{My Vico. The last baroque, father of aesthetics and of cultural studies}

ABSTRACT: True to the Viquian historical method, which favors fragments, wastes or dismissals, my reading of Vico has always focussed on the neglected and eliminated motifs of his thought, which I have reread freely, seeking above all to make them resonate in the current horizon of thought. This is the way my readings of a Vico were born, as theoretician of the body, a Baroque thinker, the father of modern aesthetics and cultural studies.

KeYwords: Vico, 350 th Anniversary, body, ingenuity, Baroque, aesthetics, cultural studies, G. Patella.

\section{Il mio Vico. Ultimo barocco, padre dell'estetica e degli studi culturali}

RIASSUNTO: Fedele al metodo vichiano che nella storia predilige i frammenti, i residui, gli scarti, la mia lettura di Vico ha sempre prediletto i motivi trascurati e rimossi del suo pensiero, che ho così riletto liberamente e cercato soprattutto di farli risuonare nell'orizzonte attuale del pensiero. Nascono così le mie letture di un Vico teorico del corpo, pensatore barocco, padre dell'estetica moderna e degli studi culturali.

Parole chiaVe: Vico, $350^{\circ}$ Anniversario, corpo, ingegno, Barocco, estetica, studi culturali, G. Patella.

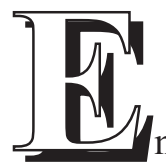

n el fondo de mi interés hacia el pensamiento de Vico siempre ha estado el intento de hacer emerger, a veces incluso de manera temeraria y forzando un poco la mano, de su obra y de su contexto histórico algunas razones de fondo

Este artículo responde a una invitación expresa por parte de la Dirección de la Revista para este volumen especial por el $350^{\circ}$ Aniversario del nacimiento de G. Vico, habiendo superado los criterios de valoración y del proceso de aceptación. 
para intentar restaurar su vitalidad y sobre todo para tratar de hacer que actúen aquí y ahora, en nuestro presente.

Partiendo de una sustancial adhesión metodológica al pensamiento viquiano, que en la historia del pasado prefiere los descartes, los residuos, los fragmentos, utilizándolos a su gusto como si fuera un "bárbaro", entre los pliegues de su pensamiento también yo me encuentro prefiriendo los restos, los jirones, los motivos descuidados y eliminados, que puedo así releer libremente, de una manera desencantada, combinarlos juntos y hacerlos resonar, incluso en la distancia, en el horizonte actual de la reflexión. Siempre me he movido en ese territorio intermedio que se abre entre la adhesión y la "profanación", por decirlo con Giorgio Agamben, entre la norma y el desvío.

Entonces, ¿qué es lo que guía mi lectura?, ¿qué encuentro en la obra de Vico para extraerlo y hacerlo jugar aquí y ahora en las tramas de nuestro tiempo?

Ante todo, lo que me llamó la atención desde la primera vez que lo leí, hace más de treinta años, fue el motivo corpóreo, el tema del cuerpo, que es un elemento descuidado, desaparecido por mucho tiempo de la historiografía filosófica, aunque central y vital para nosotros hoy, sobre el que se han concentrado desde el principio mis investigaciones.

Vico siempre ha sido considerado, con razón, el pensador de los orígenes, pero los orígenes no se entienden, sin embargo, como algo sublime y noble, como si estos fuesen la edad de oro. De hecho, por el contrario, precisamente por ese peculiar enfoque suyo de la historia que puede definirse brevemente como genealógico, por el cual se puede comprender su significado reconstruyendo el proceso de generación, las fases primarias de su desarrollo investigando el origen, los orígenes aparecen más bien como una cosa tosca, bárbara, literalmente bestial.

Volver a los orígenes, investigar el principio, desde esta perspectiva, no puede significar más que servirse de los instrumentos más adecuados para tratar de sacar a la luz los aspectos más lejanos, ocultos y remotos del pensamiento, aquello que presenta los caracteres de la oscuridad, de la obscenidad, de la violencia, lo que tiene que ver con la dimensión propia del sentido, con las pasiones, con las pulsiones bestiales, con los instintos que hunden sus propias raíces en el cuerpo.

Por lo tanto, es necesario tomar en consideración los residuos, los fragmentos, los "añicos" de humanidad, como los llama Vico, es decir, lo que generalmente se considera secundario e inesencial, o sea, los mitos, las leyendas, las costumbres, formas de decir y creencias populares, valiéndose del estudio de las lenguas, la etimología, la retórica, valorando al máximo la contribución de las facultades sensibles y perceptivas, como la memoria, la fantasía o el ingenio.

En este sentido, Vico también podría ser definido como el filósofo del comienzo, o el «poeta del alba» -como lo había definido sugestivamente Giuseppe Capograssi- y probablemente debería ser considerado uno de los padres fundadores 
de aquellas ciencias que estudian el saber y la civilización humana en sentido antropológico y más en general en sentido cultural, como explicaré mejor más adelante.

Según este nuevo acercamiento a la historia, el tiempo de los orígenes no tiene en sí ningún significado esotérico u oculto, no representa nada de puro y sutil, sino que tiene que ver con la dimensión propia del sentido, siempre ha estado involucrado con la evidencia propia del cuerpo. En esta perspectiva, el tiempo de los orígenes es más bien el lugar de la procedencia, y la procedencia, como recuerda acertadamente Foucault, siempre ha tenido que ver con el cuerpo.

¿Pero de qué cuerpo hablamos? En Vico se trata, en general, de un cuerpo entendido como un conjunto de intuiciones perceptivo-memorístico-imaginativas, un cuerpo, por tanto, originariamente estético, porque es una unidad viviente de sentido en el que hunden las raíces esas facultades memorísticas, fantásticas e ingeniosas a partir de cuya elaboración toma forma una sabiduría poética que es inmediatamente mítica e histórica a un tiempo.

Además, esta centralidad del cuerpo está bien presente y atestiguada a lo largo de todo el arco de su pensamiento, desde las obras juveniles hasta la madura obra maestra de la Ciencia nueva, donde el cuerpo se convierte en el paradigma básico de una nueva visión del mundo y de una filosofía que crece y se construye en torno al cuerpo. Desde este punto de vista, la obra maestra viquiana podría leerse como una larga reflexión sobre el cuerpo, sobre las facultades que se derivan de él, sobre la sabiduría que se origina en el cuerpo y sobre el pensamiento que el cuerpo mismo nunca deja de mirar.

El saber que se origina en el cuerpo no es, de hecho, diferente del saber de la poesía; se trata de la misma sabiduría: la sabiduría del cuerpo es sabiduría poética, tanto como es sabiduría histórica. Y el enraizamiento corpóreo del saber poético es inmediatamente evidente si se presta atención al hecho de que las facultades sobre las que se funda, es decir, sentido, imaginación, memoria e ingenio, son facultades que «hunden sus raíces en el cuerpo y toman vigor del cuerpo» (SN44, § 819). Esto significa que mental y corpóreo, en la sabiduría poética, constituyen un todo: el cuerpo, como el sentido, no es para Vico algo pasivamente inerte, sino centro y eje de energía. Si, en efecto, como niños del naciente género humano, los primeros autores de las naciones «reducían las funciones externas del ánimo a los cinco sentidos del cuerpo», los percibían «vívidos e intensos, propios de quienes tenían muy poca razón o ninguna y en cambio una robustísima fantasía» $(S N 44, \S 705)$.

El cuerpo descrito por la Ciencia nueva se puede en síntesis definir como un continuum fluido interno y externo, un tejido conectivo en el que dentro y fuera viquianamente se convierten. No se trata de una unidad corpórea cerrada en sí misma, de una carcasa mecánica entendida como límite infranqueable del pensamiento, sino de un cuerpo siempre abierto y tendido hacia algo distinto de sí mismo, provocado por lo que es exterior, animado por fuerzas, necesidades, pasiones y eventos que lo 
sacuden, que siempre lo empujan hacia afuera haciéndolo convertirse en un lugar seguro de desembocadura de las cosas, un espacio de encuentro del mundo. Se trata de un cuerpo-mundo y un cuerpo-tiempo, de un cuerpo, por tanto, plural, múltiple y colectivo. Cuerpos que se dicen de muchas maneras, cuerpos que son «cielo, tierra, mar», cuerpos que son dioses, cuerpos de la naturaleza y del universo, y cuerpos sociales que son familias, grupos, corporaciones, multitudes, gentes, pueblos, naciones, humanidad. El cuerpo es, ante todo, lugar de encuentro, trámite de socialización. Los protagonistas de la obra viquiana siempre son, de hecho, las multitudes, las colectividades, los grupos, y nunca el individuo tomado singularmente.

Esta polisemia del cuerpo, sin embargo, no es sinónimo de confusión e indistinción, porque es más cierto, escribe Vico, «que las mentes son todas iguales» y que estas «adquieren la diversidad de la diversa organización de los cuerpos y la diversa educación civil» (SN44, § 415).

De acuerdo con esta centralidad del cuerpo, el viquiano pensar poético nunca es un pensar abstracto y "espiritualizado", sino muy vívido y "corpulento". El enemigo contra el que lucha Vico con todas sus energías, y desde el comienzo de su investigación, es la deducción vacía, el puro mentalismo, la unilateralidad del método geométrico, la mera abstracción metafísica, y esto siempre en nombre de un tipo de conocimiento incorporado, por así decir, arraigado en el cuerpo, por lo tanto capaz de defender los peculiares derechos de la sensibilidad y de la corporeidad, de las facultades fantásticas e ingeniosas que se originan de él, y de una gnoseología capaz de valorar plenamente sus razones.

Esto implica que el pensamiento no desciende directamente de una entidad pura y distante como la mente, el espíritu, sino de un compromiso esencial con el cuerpo que condiciona y determina su naturaleza. En este sentido, podemos decir que la corporeidad también puede entenderse como una limitación positiva de la mente, desde el momento en que circunscribe y redimensiona las funciones puramente racionalistas cuando extiende y amplía su ejercicio precisamente en la corporeidad.

Desde este punto de vista, la dimensión de la corporeidad, con todos sus amplios matices semánticos, que asume un papel imprescindible en la nueva visión del saber y del conocimiento propuestos por la reflexión de Vico, también parece indicar la posibilidad de una nueva modalidad de pensar con el cuerpo, lo que nos recuerda, por otra parte, que cuando reflexionamos con mente pura siempre debemos tener en cuenta ese cuerpo que nosotros mismos somos, ya que nosotros mismos no somos más que una unidad de «mente, cuerpo y habla» (§ 1.045).

Por lo tanto, es en esta perspectiva general, en mi opinión, donde nace el vínculo con la disciplina de la estética, que si realmente quiere decir tal, es investigar filosóficamente la esencia de nuestras experiencias perceptivas, memorísticas y creativas en un sentido amplio, no puede ser más que una teorización del cuerpo y por eso, por tal razón, debe tomarse en serio la reflexión viquiana y reconocer en 
ella una contribución teórica de grandísimo relieve, que se pone precisamente en el lugar de origen de la estética moderna propiamente dicha.

En varios lugares y varias veces -incluso en las páginas de esta prestigiosa Revista- he insistido en sostener cómo en la reflexión viquiana, justamente a través de la exaltación de las facultades corpóreas, sensibles y perceptivas, la revalorización de los componentes fantásticos, memorísticos e ingeniosos, pone netamente en claro por primera vez en la modernidad este nexo entre cuerpo y teoría estética, reivindicando la independencia y la plena legitimidad especulativa de la dimensión del sentir y del universo fantástico y poético en el que hunde sus propias raíces, constituyendo así una contribución fundamental para el nacimiento de la estética como disciplina filosófica moderna. Donde, sin embargo, hay que entender la estética no en la acepción tradicional de especifica doctrina filosófica que se ocupa de lo bello y del arte, sino en sentido etimológico, pero también en un sentido más amplio, como reflexión general sobre las formas de la sensibilidad, como una teoría del sentir.

La reflexión estética viquiana siempre se me ha aparecido como una reflexión unitaria en la que se reconocen los peculiares derechos de la sensibilidad, a través de la exaltación de las facultades corpóreas, sensibles y perceptivas, la puesta en valor de la fantasía, de la memoria, del ingenio como categorías cognoscitivas: se afirma, por tanto, en conjunto, el valor del conocimiento fantástico y sostenido por su plena legitimidad teórica. Vico es en efecto, capaz de conferir a estas facultades corpóreas una dignidad epistemológica al menos pareja al intelecto y a la razón, describiendo además el exacto funcionamiento según una peculiar consideración tanto ontogénica como filogenética. En este sentido, se puede decir que la reflexión estética viquiana, completamente realizada en la Ciencia nueva, pero ya anticipada en las obras precedentes, constituye uno de los principales momentos de elaboración filosófica que contribuyen al nacimiento de la estética en la acepción moderna del término, representando así el fundamento oculto, descuidado, y sin embargo decisivo, antes de que la estética moderna fuese oficialmente bautizada con este nombre e incluso antes de que Kant le hiciese la "crítica", por así decir, elevándola al rango de disciplina filosófica junto a las otras. Afirmando, en síntesis, la plena dignidad y legitimidad especulativa del universo fantástico e ingenioso y moviéndose, sobre todo, hacia una teorización estética que identifica en el cuerpo el propio núcleo significativo, la reflexión viquiana representa, en efecto, un primer intento completo de definición del horizonte teórico de la estética moderna. ${ }^{1}$

Ahora, se reconoce que este vínculo de Vico con la estética es un "descubrimiento" identificado por primera vez por Benedetto Croce, pero esta realmente

1. La idea de Vico como padre de la estética moderna se desarrolló inicialmente en mi Senso, corpo, poesia. G. Vico e l'origine dell'estetica moderna, Guerini, Milán, 1995. 
feliz intuición crociana en mi interpretación se retoma para ser deconstruida y distorsionada, vuelta así contra el propio Croce. Porque parece tanto más sostenible y verdadera cuanto más se aleja de la impostación neoidealista que la sostiene.

De hecho, desde mi punto de vista, la estética de Vico no representa el punto de partida del Romanticismo, el «siglo decimonónico en ciernes» o la fase auroral de la vida del espíritu, como quería Croce en clave idealista, sino más bien el punto de llegada del Barroco, es decir, de una nueva filosofía del sentir reunida en torno a la centralidad del sentido, del cuerpo y del ingenio. No se trata de entender la estética crocianamente como una peculiar teoría de la poesía o forma del espíritu, sino viquianamente, como una reflexión filosófica sobre los aspectos sensitivos, afectivos, perceptivos de la experiencia, y por consiguiente globalmente como una reflexión sobre el cuerpo y sobre la dimensión del sentir que está en el centro de la cultura del Barroco.

En línea con una tradición hermenéutica minoritaria, pero no poco influyente (Anceschi, De Giovanni, Battistini...), también según yo, el pensamiento de Vico representa el punto de llegada filosóficamente más maduro, la consumación filosófica de la cultura del Barroco, o sea, de aquella extraordinaria experiencia cultural recogida en la insignia de la facultad del ingenio -facultad creadora e innovadora por excelencia- de la revalorización de la metáfora, de las potencialidades cognitivas de la fantasía, de la poesía, del mito, del sentido común. Con su lógica poética, que acoge, repiensa y hace propia la mejor tradición filosófico-poética de los siglos XVIXVII transformándola a la luz de una fundación filosófica fuerte, que sanciona -como hemos visto- el nacimiento de la estética moderna, Vico encarna la síntesis filosófica última del Barroco, ${ }^{2}$ el culmen teórico de esa cultura que hace del ingenio su principio dinámico. El ingenio es facultad sintética e inventiva, es capaz de encontrar relaciones inéditas entre las cosas, de unir y poner juntas cosas diversas y distantes, produciendo tanto deleite por la sorpresa de los acercamientos como nuevo conocimiento. Pero el conocimiento solo puede partir de los sentidos, y es exactamente en torno al centro focal representado por la categoría del sentido como pueden ser leídas las principales formas culturales barrocas, ${ }^{3}$ por lo que se puede hablar de una general rehabilitación del sentido gracias a la cual la sensibilidad resulta investida de nuevos significados, no ya entendida como mera pasividad, sino como dimensión central del pensar y del conocer, a la que se le confiere la plena dignidad de la idea. De aquí también la progresiva afirmación de un sentido corporal y corpulento de la reflexión, de una sensibilidad reflexiva y de una filosofía del sentido, por así decir,

2. Sobre el movimiento "barroco" del pensamiento viquiano reenvío a G. PATella, Giambattista Vico tra Barocco e Postmoderno, Mimesis, Milán, 2005.

3. J.A. MARAVAll, en su importante trabajo La cultura del Barocco (trad. it. il Mulino, Bolonia, 1985), escribe (p. 107): «La cultura barroca es un pragmatismo, de base más o menos inductiva, ordenado por la prudencia». Sobre los caracteres de la cultura barroca véase también el exhaustivo trabajo de A. BATTISTINI, Il Barocco, Salerno editrice, Roma, 2000. 
por el cual el viquiano advertir «con ánimo perturbado y conmovido» no solo se convierte en un momento indispensable también del reflexionar «con mente pura», sino que adquiere una legitimidad propia y una autonomía sin las cuales no se daría propiamente ni poesía ni tampoco historia y civilización.

El pensamiento abierto y multipolar de Vico, que mantiene ingeniosamente juntos elementos diversos y distantes, se inserta perfectamente en esa sistemática multipolaridad que es la forma propia del Barroco, para la cual, en general, no vale un principio hermenéutico rígido que constriñe el análisis en una monolítica uniformidad de lectura. Vico es así, contemporáneamente hijo, heredero y testigo altísimo de esa experiencia cultural polifónicamente articulada en la que conviven en un especialísimo crisol lo antiguo y lo moderno, lo viejo y lo nuevo, el microcosmos y el espacio infinito. Una cultura en la cual trascendencia e historia, filosofía y filología, teología y ciencia, verdadero y cierto, reclamándose recíprocamente, viquianamente se convierten. Nos encontramos así frente a un pensador no cronológicamente ligado a la edad barroca, pero en la extrema conciencia teórica del Barroco, el punto máximo de llegada, su consumación filosófica. Y, puesto que, como sostenía Nietzsche, es en la consumación donde se revelan las raíces, quizá es justamente con Vico con quien se manifiesta la esencia más verdadera del Barroco mismo. ${ }^{4}$

La posibilidad de interpretar a Vico en clave barroca no debe ser considerada sin embargo como algo que mira al pasado, desde el momento en que si hoy interrogamos al pensamiento de Vico lo hacemos no por un mero gusto anticuario, sino -como decía al inicio- con la intención de lanzar luz sobre las cuestiones filosóficas que más nos acucian y que agitan nuestro tiempo. Y en tiempos de retorno del interés en las comparaciones con el Barroco, como resultado más interesante incluso que algunas formas de la reflexión contemporánea, ${ }^{5}$ se podría pensar en una actualizada terapia viquiana, o quizá, por así decir, "neobarroca", basada en los principios de la historicidad y de la flexibilidad, en el redescubrimiento de los derechos de la corporeidad y de la sensibilidad y en el potenciamiento de las facultades conectivas como la fantasía, la memoria y el ingenio, capaz de configurar una nueva visión del saber, fundada en la aportación paritaria de las diversas facultades y disciplinas humanas, dando vida a una experiencia distinta de la racionalidad, más amplia y articulada que la tradicional, y a una experiencia diferente de la modernidad misma.

En este sentido, se podría decir que cuanto más nos esforzamos en colocar a Vico en su tiempo, en la cultura en la que ahonda sus raíces, tanto más llegamos a dar-

4. He vuelto también recientemente a la relación de Vico con el Barroco en el ensayo «Dal Barocco al Barocco. Vico e Gracián», Rocinante, n. 11, 2018.

5. Recientemente Gilles Deleuze, en el contexto de la interpretación del pensamiento de Leibniz, ha relanzado sugerentemente la categoría de barroco como clave de lectura de diversas expresiones culturales contemporáneas y ha avanzado la idea de un "neobarroco" filosófico como nuevo paradigma interpretativo: cfr. G. DeLEUZe, Le plie: Leibniz et le Baroque, Ed. de Minuit, París, 1988. 
nos cuenta de su sorprendente actualidad. No se trata, de hecho, de hacer de Vico un anticipador, un precursor, ni tampoco un pionero, un caballero solitario, sino más bien de interpretarlo como un pensador que suministra respuestas a problemas que son todavía nuestros, respuestas a estos problemas que se revelan de extraordinaria actualidad.

Siempre en favor de la estrategia barroca del ingenio, que consiste en aproximarnos lo distante conservando sin embargo su lejanía, la última fase de mis investigaciones viquianas ha llegado finalmente a proyectar al pensador barroco sobre el escenario cultural contemporáneo, acercando la visión del saber y de la cultura que emerge de la obra viquiana a la perspectiva de investigación avanzada en los últimos años por el universo de los llamados estudios culturales. ${ }^{6}$

Partiendo del presupuesto de que la obra de Vico representa un punto de referencia imprescindible no solo en el ámbito de la historia de la cultura de todos los tiempos, sino además de gran actualidad todavía hoy para cuantos consideran la cultura ya sea como objeto o como método de estudio privilegiado, no es difícil acercar la reflexión viquiana a la perspectiva de investigación que se resume bajo el nombre de "cultural studies", sobre todo si se estudian temas como ingenio, tópica, imagen, cuerpo, poder, autoridad, por citar solo algunos, que resuenan ampliamente en el panorama de los estudios culturales y en el horizonte global de la reflexión contemporánea, haciendo así de Vico uno de los lejanos padres fundadores de este tipo de estudios.

En el ámbito de los cultural studies, donde se ha teorizado, por ejemplo, en el concepto de "articulación", me parece que pueden individuarse las trazas más evidentes de la teorización del ingenio barroco y del método tópico viquiano, avanzando la idea de que para producir nuevas fronteras de investigación es preciso proceder mediante la feliz conexión de elementos de naturaleza diversa, que pueden ser aproximados y entrar en relación en determinadas circunstancias y en particulares condiciones, con la condición de salvaguardar su diferencia. Y esto vale sobre todo para las investigaciones de frontera, que a menudo parecen tanto más originales e innovadoras cuanto más se inclinan hacia las zonas marginales y los confines más alejados de los conocimientos tradicionales.

Desde esta perspectiva general, podría por tanto concluirse que, una vez más, desde lo más profundo de la cultura barroca, todo lo contrario de oscura y polvorienta, Vico habla de un modo insospechado a la sensibilidad contemporánea, contribuyendo así a delinear los trazos de una nueva práctica cultural y a suministrar una preciosa contribución para repensar nuestra actual condición cultural.

\section{[Traducción del italiano por María José Rebollo Espinosa]

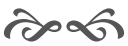

6. He empezado a desarrollar esta relación entre Vico y los estudios culturales precisamente en esta Revista, en el ensayo «Giambattista Vico padre de los estudios culturales» (Cuadernos sobre Vico, n. 28-29, 2014-2015), y he continuado después en el Bollettino del Centro di studi vichiani de 2018 y para el próximo número del 2019. 